\title{
Probability and determinants of relapse after discontinuation of inhaled corticosteroids in patients with COPD treated in general practice
}

\author{
T.R.J. Schermer ${ }^{a, *}$, A.J.C. Hendriks ${ }^{b}$, N.H. Chavannes ${ }^{b}$, \\ P.N.R. Dekhuijzen ${ }^{c}$, E.F.M. Wouters ${ }^{d}$, H. van den Hoogen ${ }^{a}$, \\ C.P. van Schayck ${ }^{b}$, C. van Weel ${ }^{a}$
}

a Department of General Practice/Family Medicine, University Medical Centre Nijmegen, 229-HAG, P.O. Box 9101, 6500 HB Nijmegen, The Netherlands

b Department of General Practice/Family Medicine, University of Maastricht, Maastricht, The Netherlands

c Department of Pulmonology, University Medical Centre Nijmegen, Nijmegen, The Netherlands

d Department of Pulmonology, University Hospital Maastricht, Maastricht, The Netherlands

\section{KEYWORDS}

Pulmonary disease; Chronic obstructiveanti-inflammatory agents; Steroidal-withholding treatment
Summary Objective: The objective of the study was to assess the probability, and explore determinants of adverse respiratory outcome after discontinuation of inhaled corticosteroid (ICS) treatment in subjects with chronic obstructive pulmonary disease (COPD) diagnosed and treated in general practice. Design: Prospective unblinded ICS withdrawal study. Subjects: 201 ICS treated COPD patients with various degrees of airflow limitation from 45 Dutch general practices. Main outcome measures: Probability of and time to exacerbation or unremitting worsening of respiratory symptoms after ICS discontinuation. Results: Mean age was 60.6 (S.D. 9.5) years, post-bronchodilator forced expiratory volume in $1 \mathrm{~s}\left(\mathrm{FEV}_{1}\right) 65.6$ (S.D. 15.7) \% predicted. Overall probability of adverse respiratory outcome after ICS discontinuation was 0.37 (95\% confidence interval $(\mathrm{Cl}) 0.31,0.44)$. Survival analysis showed that age, gender, smoking status and reversibility of airflow limitation were independent predictors of adverse respiratory outcome. For females, the adjusted hazard ratio was $2.14(95 \% \mathrm{Cl} 1.31,3.50)$ compared to males. For age, the hazard ratio was $1.05(95 \% \mathrm{Cl} 1.02,1.08)$ per year lived. Conclusion: Discontinuation of inhaled corticosteroids may harm patients with COPD. The probability of an adverse respiratory outcome may be higher in women, elderly patients, smokers and patients with higher bronchodilator reversibility while on inhaled steroid treatment.

(c) 2003 General Practice Airways Group. Published by Elsevier Ltd. All rights reserved.

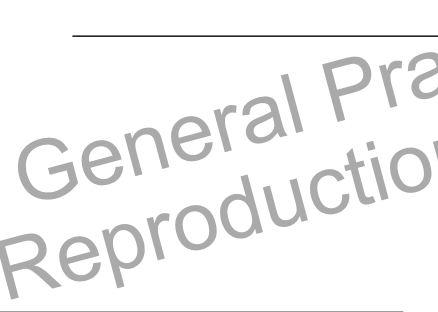

*Corresponding author. Tel.: +31-24-3614611; fax: +31-24-3541862.

E-mail address: t.schermer@hag.umcn.nl (T.R.J. Schermer).

\section{Introduction}

Despite a number of recent clinical studies [1-4], the benefits of inhaled corticosteroids in patients with chronic obstructive pulmonary disease (COPD) are still debated. No effect on lung function decline has been established, but inhaled steroids seem to 
slow-down health status deterioration and reduce acute exacerbations [1,4]. According to recent global guidelines for COPD management, inhaled steroids should be reserved for symptomatic patients with a documented spirometric response to steroids and for those with moderate to severe airflow limitation and repeated exacerbations which require antibiotic and/or prednisolone treatment [5]. At this time, however, many more patients with COPD in general practice are treated with inhaled corticosteroids, most of them for a number of years already $[6,7]$. Regular inhaled steroid treatment is probably superfluous in a considerable number of patients and ought to be discontinued. This may cause problems, however, as adverse effects of withdrawal of inhaled steroid therapy in patients with COPD have been reported [8-10], making it likely that at least some patients are harmed. For that reason, the possibility to predict adverse respiratory outcome would enable a more rational and safe way of withdrawing inhaled steroids in order to modify current ineffective prescription practices. Therefore, the objectives of this study were to assess the probability of an adverse respiratory outcome after discontinuation of regular inhaled steroid treatment in primary care patients with COPD, and to explore patient characteristics associated with the probability of exacerbation or relapse after inhaled steroid withdrawal.

\section{Methods}

\section{Subjects and recruitment}

We studied 232 subjects with COPD diagnosed and treated by their general practitioner (GP) (Fig. 1). All subjects entered the washout phase of the COPD on Primary Care Treatment (COOPT) trial [11], which investigates the effectiveness of inhaled fluticasone propionate and oral $\mathrm{N}$-acetylcysteine in COPD. Study participants were recruited from 45 general practices in the south-eastern part of The Netherlands. Eligibility criteria were: chronic dyspnea, sputum production and cough for at least three consecutive months per year during the previous 2 years [12]; current or former smoker; either post-bronchodilator forced expiratory volume in $1 \mathrm{~s}\left(\mathrm{FEV} V_{1}\right)<90 \%$ of the predicted value, or FEV $/ F V C<88 \%$ of the predicted value' ( $89 \%$ for women) [12]; never treated fon asthma, allergic rhinitis or atopic rash; no severe comorbid conditions. Subjects with a $\mathrm{FEV}_{1}<35 \%$ of the predicted value were excluded.

\section{Study procedures and measurements}

The study was approved by the medical ethics review board of the University Medical Centre, Nijmegen. All subjects gave written informed consent. In order to be able to assess eligibility of subjects for the subsequent clinical trial, those on inhaled steroids had to go through a steroid washout of at least 3 months. Trial candidates requiring a washout were categorized as: low inhaled steroid dosage $(<500 \mu \mathrm{g}$ fluticasone propionate, $<800 \mu \mathrm{g}$ budesonide or beclomethasone dipropionate per day); intermediate dosage (fluticasone propionate $500-1000 \mu \mathrm{g}$, budesonide or beclomethasone dipropionate $800-1600 \mu \mathrm{g}$ ); high dosage ( $\geq 1000 \mu \mathrm{g}$ fluticasone propionate, $\geq 1600 \mu \mathrm{g}$ budesonide or beclomethasone dipropionate).

Subjects were instructed to contact their GP if they noted a worsening of their respiratory symptoms for at least three consecutive days. Subjects had to had been clinically stable for at least 6 weeks prior to steroid withdrawal, i.e. should not have had an exacerbation during this period. The steroid washout formally terminated on the day of the visit at the lung function laboratory where the eligibility criteria for trial participation were verified. Adverse respiratory outcome was defined as either

(1) The occurrence of an acute exacerbation of COPD, diagnosed and treated with prednis(ol)one and/or a course of antibiotics by a general practitioner or chest physician; or

(2) an episode of unremitting worsening of respiratory symptoms of at least three consecutive days which led the subject to seek medical attention from his or her general practitioner and which resulted in relapse into inhaled steroid treatment.

General practices staffs were trained in performing spirometry before the study and were equipped with an electronic spirometer (Micro Medical Ltd., Rochester, Kent, UK) and spirometry software $\left(\right.$ Spirare $^{\circledR}$, Diagnostica Ltd., Oslo, Norway). Spirometry was performed before and after administration of $400 \mu \mathrm{g}$ salbutamol dosisaerosol

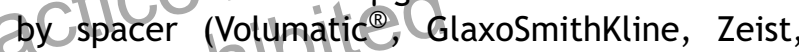
The Netherlands). Reversibility of airflow limitation was calculated as the percentage change between pre- and post-bronchodilator $\mathrm{FEV}_{1}$ values and as the difference between the pre- and post-bronchodilator percentage predicted $\mathrm{FEV}_{1}$ [13]. European Community for Steel and Coal reference values were used to calculate predicted values [13]. 


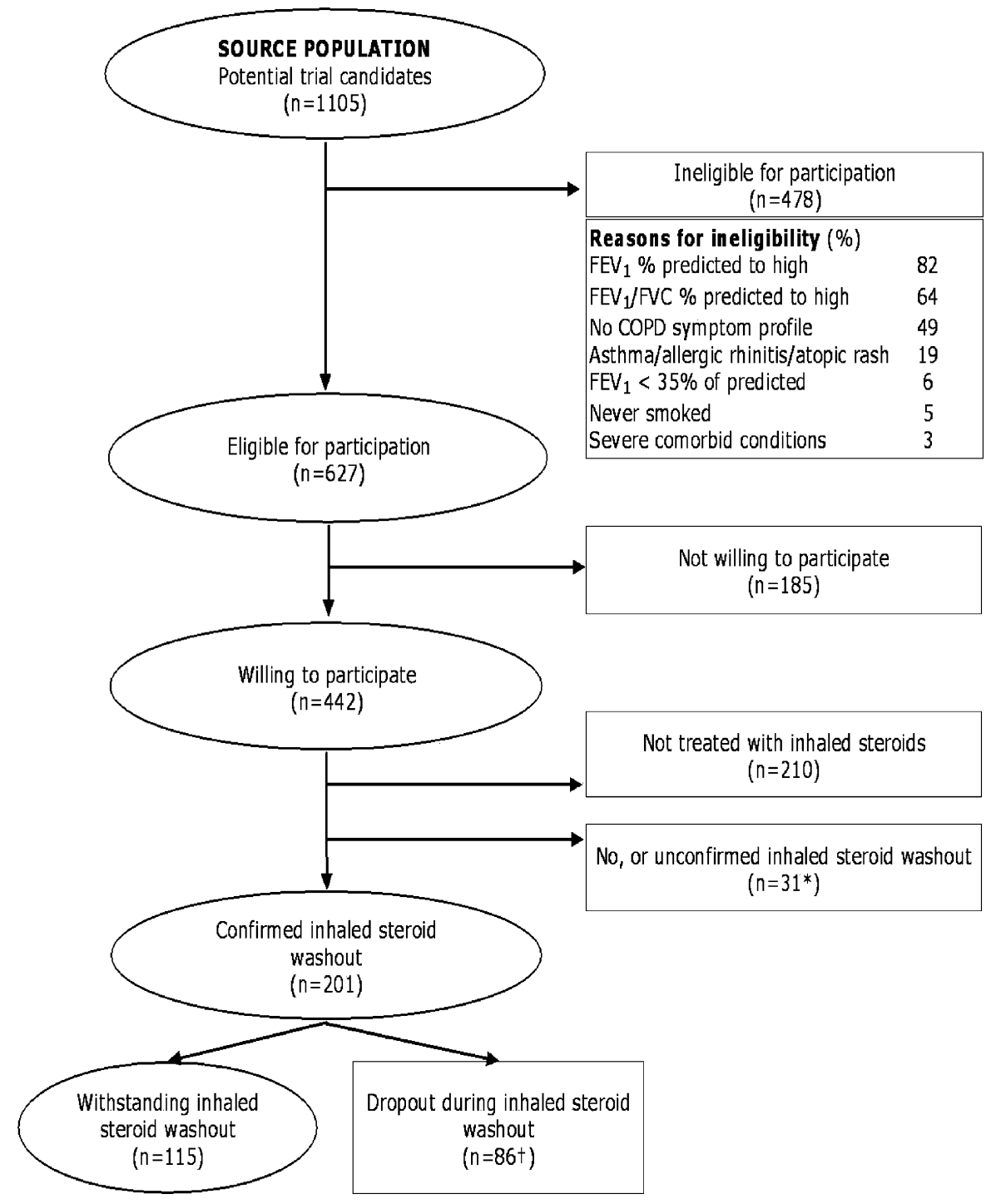

Figure 1 Subject recruitment and drop out during inhaled steroid washout (*) including 11 subjects lost to follow-up, 17 subjects without confirmation of inhaled steroid discontinuation and 3 subjects where a general practitioner or chest physician advised against inhaled steroid withdrawal $(\dagger)$ including $(n=75)$ adverse respiratory outcome.

\section{Statistical analysis}

SPSS for Windows (Release 9.0.1) was used for analyses. Appropriate statistical tests were used to compare baseline characteristics between steroid dosage subgroups and subjects with and without adverse respiratory outcome. The relationship between the time to adverse respiratory outcome after steroid withdrawal and a number of explanatory variables was analysed asing multivariable Cox proportional hazards modelling [14]. Suryival time was defined as the number of days between the start of steroid withdrawal and onset of adverse respiratory outcome. Those withstanding the washout period without adverse respiratory events were treated as right censored cases. Explanatory variables included in the multivariable model were: age; gender; smoking status (current/former); duration of disease; self-reported exacerbation rate in the previous 2 years $(0,1$, or $\geq 2$ exacerbations); $\mathrm{FEV}_{1}$ as percentage predicted; $\mathrm{FVC}$ as percentage predicted; $\mathrm{FEV}_{1} \angle \mathrm{FVC}$ ratio $\geq 70 \%$ or $<70 \%$; reversibility of $\mathrm{FEV}_{1}<9 \%$ or $\geq 9 \%$. Backward elimination was used to remove covariates with a Wald statistic test probability $\geq 0.10$ from the model.

A priori, we suspected confounding by indication [15] with regard to the dosage of inhaled steroids before discontinuation: subjects on a high dose of inhaled steroids were more likely to be in a worse respiratory condition than subjects using a low or intermediate dosage. Therefore, a proportional hazards model containing all first order interaction 
terms with baseline inhaled steroid dosage and the explanatory variables was considered first. Because this model showed significant interaction for age, reversibility and $\mathrm{FEV}_{1} / \mathrm{FVC}$, we decided to construct separate models for each of the three inhaled steroid dosage subgroups, next to the model applicable to the total study population.

\section{Results}

\section{Population characteristics and inhaled steroid withdrawal}

Discontinuation of inhaled steroid treatment was intended in 232 subjects (Fig. 1). Eleven (5\%) subjects were lost to follow-up. In 17 (7\%) subjects, the actual discontinuation of inhaled steroid treatment could not be confirmed. In three $(1 \%)$ subjects, withdrawal of inhaled steroids was advised against by a consulting chest physician. Table 1 shows baseline characteristics of the remaining 201 subjects by subgroup of inhaled steroid dosage. Most subjects $(54 \%)$ were on a moderately high dosage of inhaled steroids. Significant airflow limi- tation (post-bronchodilator $\mathrm{FEV}_{1}<80 \%$ of predicted value) was present in 156 (78\%) subjects. Forty-six (23\%) subjects had mild, 105 (52\%) moderate, and $50(25 \%)$ severe airflow limitation. Baseline steroid dosage was significantly related to preand post-bronchodilator $\mathrm{FEV}_{1}$ and $\mathrm{FEV}_{1} / \mathrm{FVC}$ values (Table 1).

\section{Adverse respiratory outcome}

Of the 201 study subjects, 86 (43\%) dropped out after inhaled steroid treatment was discontinued, $75(87 \%)$ due to respiratory causes and $11(13 \%)$ for other reasons. Other reasons for dropping out were: lack of motivation (8); acute and serious illness of spouse (1); intervening elective surgery (1); and diagnosed malignancy (1). Of the respiratory dropouts, $54(72 \%)$ were due to an acute exacerbation and $21(28 \%)$ due to unremitting worsening of respiratory symptoms. Of all adverse respiratory outcomes, $11(15 \%)$ occurred in the low, $43(57 \%)$ in the intermediate and $21(28 \%)$ in the high steroid dosage subgroup (Table 2 ). The overall probability of dropping out due to respiratory causes was 0.37 (95\% confidence interval $(\mathrm{Cl}) 0.31$,

Table 1 Baseline characteristics of subjects with a general practice-based diagnosis of COPD and confirmed discontinuation of inhaled steroid treatment by baseline dosage of inhaled steroids. Values are means (S.D.) unless stated otherwise.

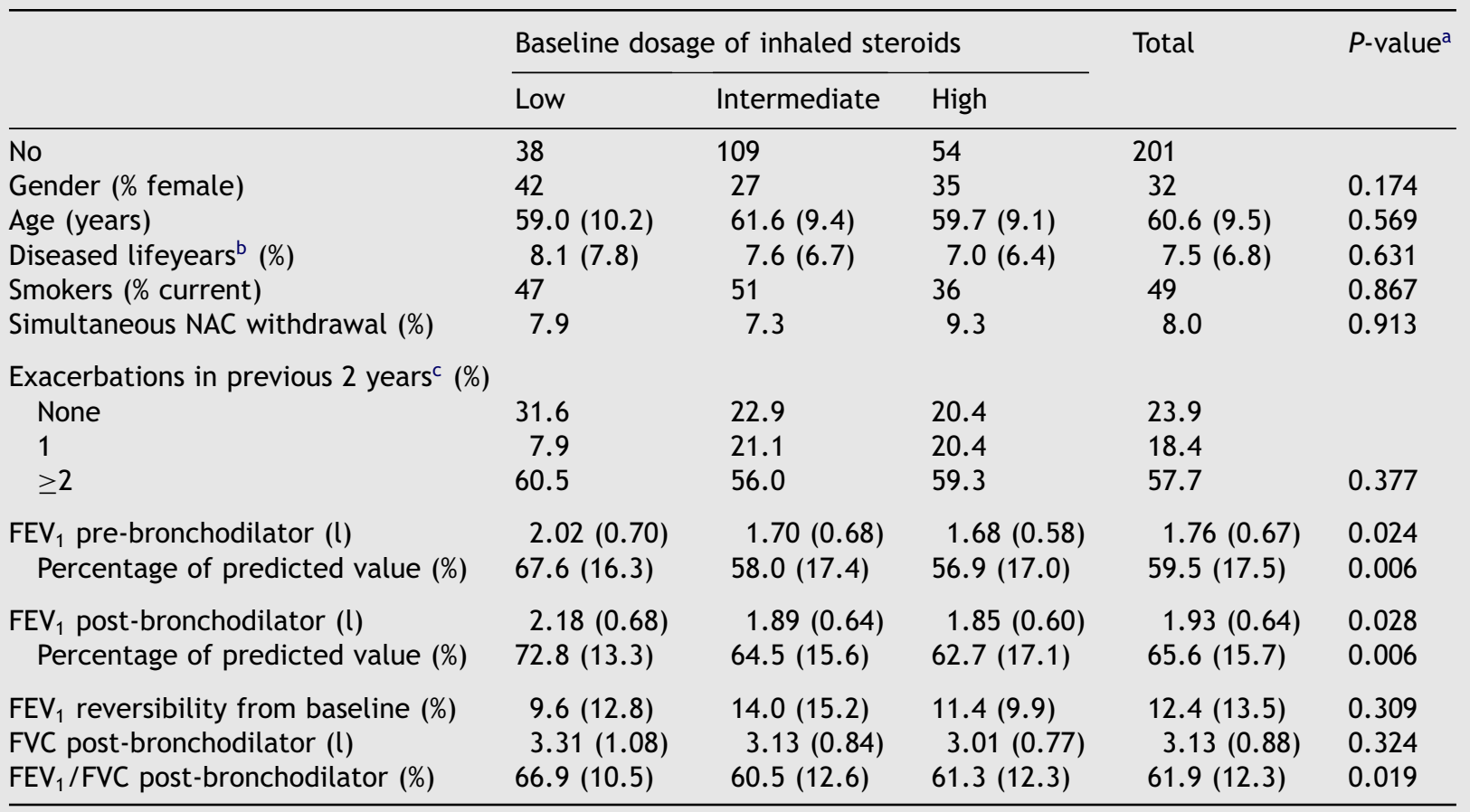

NAC: $\mathrm{N}$-acetylcysteine; $\mathrm{FEV}_{1}$ : forced expiratory volume in one second; FVC: forced vital capacity.

a Significance level of difference between inhaled steroid dosage subgroups.

${ }^{\mathrm{b}}$ Number of years since initial diagnosis of COPD as a proportion of age.

c Self-reported by study subjects. 
Table 2 Univariate comparison of subjects with and without an adverse respiratory outcome after discontinuation of inhaled steroid treatment. Values are means (S.D.) unless stated otherwise.

\begin{tabular}{|c|c|c|c|}
\hline & \multicolumn{2}{|c|}{ Adverse respiratory outcome } & \multirow[t]{2}{*}{$P$-value } \\
\hline & Yes $(n=75)$ & No $(n=126)$ & \\
\hline \multicolumn{4}{|l|}{ General characteristics } \\
\hline Gender (\% female) & 40.0 & 27.0 & 0.054 \\
\hline Age (years) & 62.5 & 59.4 & 0.028 \\
\hline Smokers (\% current) & 47.6 & 50.7 & 0.676 \\
\hline Years since diagnosis ${ }^{\mathrm{a}}(\%)$ & $11.6(9.2)$ & $13.4(13.2)$ & 0.266 \\
\hline \multicolumn{4}{|l|}{ Exacerbations in past 2 years ${ }^{\mathrm{b}}(\%)$} \\
\hline None & 23.0 & 25.3 & \\
\hline 1 & 17.5 & 20.0 & \\
\hline 2 or more & 59.5 & 54.7 & 0.793 \\
\hline \multicolumn{4}{|c|}{ Withdrawal of medication } \\
\hline \multicolumn{4}{|c|}{ Dosage inhaled steroids at time of withdrawal (\%) } \\
\hline Low & 14.7 & 21.4 & \\
\hline Intermediate & 57.3 & 52.4 & \\
\hline High & 28.0 & 36.2 & 0.495 \\
\hline Simultaneous NAC withdrawal (\%) & 10.7 & 6.3 & 0.274 \\
\hline \multicolumn{4}{|l|}{ Lung function } \\
\hline FEV 1 reversibility (baseline) (\%) & $14.9(16.5)$ & $11.0(11.3)$ & 0.047 \\
\hline FEV 1 reversibility (predicted) (\%) & $7.13(7.38)$ & $5.48(5.66)$ & 0.076 \\
\hline $\mathrm{FEV}_{1}$ pre-bronchodilator $(\mathrm{l})$ & $1.69(0.68)$ & $1.85(0.64)$ & 0.010 \\
\hline Percentage of predicted value (\%) & $57.1(17.8)$ & $60.9(17.2)$ & 0.138 \\
\hline $\mathrm{FEV}_{1}$ post-bronchodilator $(\mathrm{l})$ & $1.79(0.66)$ & $2.01(0.62)$ & 0.018 \\
\hline Percentage of predicted value (\%) & $64.3(16.7)$ & $66.4(15.5)$ & 0.360 \\
\hline FVC pre-bronchodilator (l) & $2.64(0.90)$ & $2.98(0.81)$ & 0.006 \\
\hline Percentage of predicted value (\%) & $76.1(17.2)$ & $79.0(15.6)$ & 0.223 \\
\hline FVC post-bronchodilator (l) & $2.93(0.90)$ & $3.25(0.84)$ & 0.011 \\
\hline Percentage of predicted value (\%) & $84.4(16.3)$ & $86.0(15.2)$ & 0.476 \\
\hline $\mathrm{FEV}_{1} / \mathrm{FVC}$ pre-bronchodilator (\%) & $60.7(13.1)$ & $62.0(11.9)$ & 0.493 \\
\hline Percentage of predicted value (\%) & 79.4 (17.0) & $80.5(14.9)$ & 0.618 \\
\hline $\mathrm{FEV}_{1} / \mathrm{FVC}$ post-bronchodilator (\%) & $61.5(12.5)$ & $62.2(12.2)$ & 0.685 \\
\hline Percentage of predicted value (\%) & $80.3(15.9)$ & $80.8(15.2)$ & 0.827 \\
\hline
\end{tabular}

NAC: $\mathrm{N}$-acetylcysteine; $\mathrm{FEV}_{1}$ : forced expiratory volume in $1 \mathrm{~s}$; FVC: forced vital capacity.

${ }^{a}$ Number of years since initial diagnosis of COPD as a proportion of age.

b Self-reported by study subjects.

0.44). Within the low, intermediate and high steroid dosage subgroups this probability was $0.29(95 \% \mathrm{Cl}$ $0.15,0.43), 0.39$ ( $95 \% \mathrm{Cl} 0.30,0.48)$, and 0.39 ( $95 \%$ $\mathrm{Cl} 0.26,0.52$ ), respectively. The median (interquartile range) number of days until adverse respiratory outcome was 43 (66), 42 (49) and 22 (53) for the low, intermediate and high steroid dosage subgroups $(P=0.456)$, respectively.

\section{Explanatory variables associated with} adverse respiratory outcome

Univariately, gender, age, reversibility of airflow limitation and pre- and post-bronchodilator FEV 1 and FVC values differed between those with and without adverse respiratory outcome (Table 2).
Subjects experiencing an adverse respiratory outcome tended to be more often female, were older, showed a higher baseline bronchodilator reversibility and had lower FEV 1 and FVC values.

Multivariable survival analysis indicated that the risk of adverse respiratory outcome was higher for females and that the risk increased with progressing age (Fig. 2). The hazard ratio for females was $2.14(95 \% \mathrm{el} 1.31,3.50)$ compared to males (Table 3). For age, the hazard ratio was 1.05 (95\% $\mathrm{Cl} 1.02,1.08)$ per year of increased age. When analysed separately for the baseline inhaled steroid dosage subgroups, age, gender, smoking status and reversibility were independent predictors for adverse respiratory outcome in one or more subgroups

(Table 3).

Copyright GPIAG, reproduction prohibited 


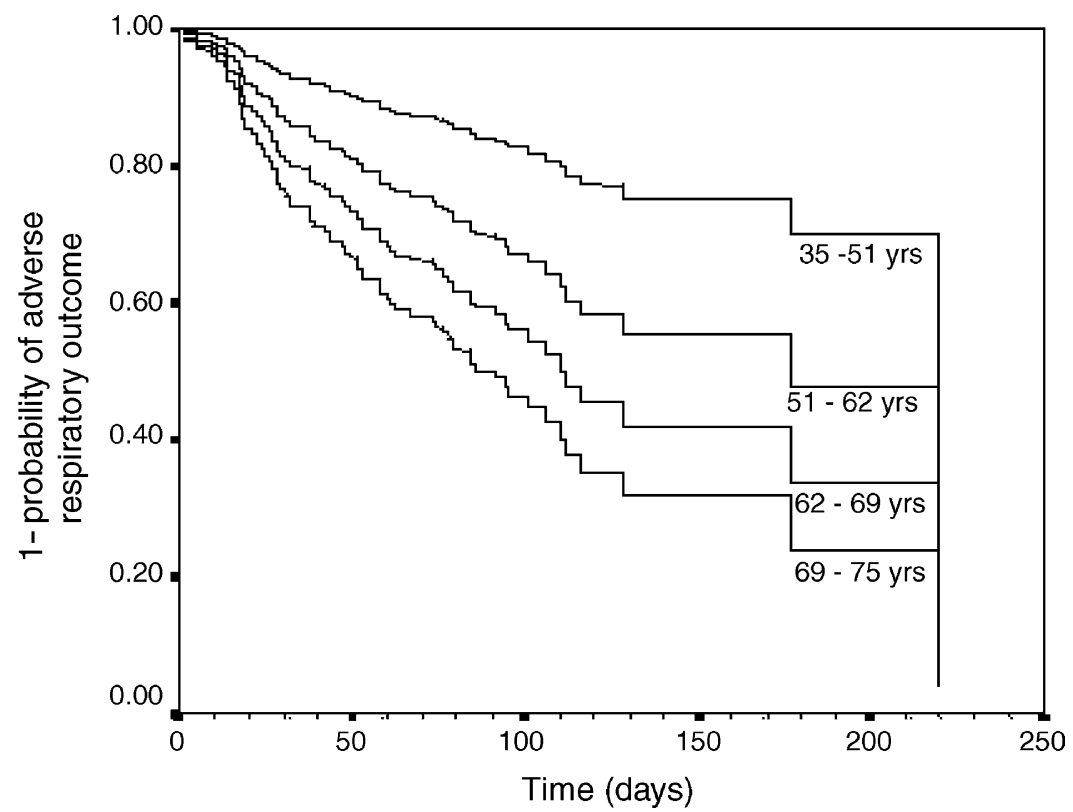

Figure 2 Adjusted survival curves after discontinuation of inhaled steroid treatment in subjects with a general practice based diagnosis of COPD $(n=201)$ by age quartile.

Table 3 Results of multivariable proportional hazards analyses.

\begin{tabular}{|c|c|c|c|c|c|c|}
\hline & $\begin{array}{l}\text { Explanatory } \\
\text { variable }\end{array}$ & $\begin{array}{l}\text { Reference } \\
\text { category }\end{array}$ & $\beta$ coefficient & $P$-value & $\begin{array}{l}\text { Hazard } \\
\text { ratio }\end{array}$ & $95 \% \mathrm{Cl}$ \\
\hline \multicolumn{7}{|l|}{ Total study population $(n=201)$} \\
\hline 75 (37\%) adverse outcome & $\begin{array}{l}\text { Age } \\
\text { Gender }\end{array}$ & $\begin{array}{l}1 \text { year increase } \\
\text { Male }\end{array}$ & $\begin{array}{l}0.048 \\
0.762\end{array}$ & $\begin{array}{r}<0.001 \\
0.002\end{array}$ & $\begin{array}{l}1.05 \\
2.14\end{array}$ & $\begin{array}{l}1.02,1.08 \\
1.31,3.50\end{array}$ \\
\hline \multicolumn{7}{|l|}{ By inhaled steroid dosage subgroup } \\
\hline $\begin{array}{l}\text { Low dosage }(n=38) \\
11(29 \%) \text { adverse outcome }\end{array}$ & Age & 1 year increase & 0.109 & 0.008 & 1.11 & $1.03,1.20$ \\
\hline $\begin{array}{l}\text { Intermediate dosage }(n=109) \\
43(39 \%) \text { adverse outcome }\end{array}$ & $\begin{array}{l}\text { Age } \\
\text { Gender } \\
\text { Smoking }\end{array}$ & $\begin{array}{l}1 \text { year increase } \\
\text { Male } \\
\text { Non-smoker }\end{array}$ & $\begin{array}{l}0.056 \\
0.810 \\
0.718\end{array}$ & $\begin{array}{l}0.005 \\
0.022 \\
0.030\end{array}$ & $\begin{array}{l}1.06 \\
2.25 \\
2.05\end{array}$ & $\begin{array}{l}1.02,1.10 \\
1.13,4.49 \\
1.07,3.93\end{array}$ \\
\hline $\begin{array}{l}\text { High steroid dosage }(n=54) \\
21(39 \%) \text { adverse outcome }\end{array}$ & $\begin{array}{l}\text { Gender } \\
\text { Reversibility }\end{array}$ & $\begin{array}{l}\text { Male } \\
\text { Irreversible }\end{array}$ & $\begin{array}{l}0.970 \\
1.166\end{array}$ & $\begin{array}{l}0.033 \\
0.013\end{array}$ & $\begin{array}{l}2.64 \\
3.21\end{array}$ & $\begin{array}{l}1.08,6.45 \\
1.28,8.05\end{array}$ \\
\hline
\end{tabular}

$\mathrm{Cl}$ : confidence interval.

\section{Discussion}

This study adds information to the limited body of knowledge with regard to the effects and risks of discontinuation of inhaled steroid treatment in patients with COPD. To our knowledge, no previous withdrawal studies have been performed in a primary care COPD population. All subjects in our study matched the 'classic' clinical profile of COPD, i.e. reported chronic sputum production and persistent cough for at least the previous 2 years.
Moreover, some degree of persistent airflow limitation was present in all subjects and all were current orformer smokers. We aimed to avoid inclusion of subjects with unambiguous asthma by excluding those previously treated for asthma, allergic rhinitis or atopic rash. Still, as both COPD and asthma show a high prevalence in the general practice population and smoking occurs in both groups of patients [16,17], coexistence of COPD and clinical features of asthma in the same subject is likely to have occurred in this study. Because asthma ttp://www.thepcrj.com Copyright GPIAG, reproduction prohibited 
and COPD share clinical similarities, it is virtually impossible to differentiate patients with chronic bronchitis and/or emphysema who have partially reversible airway obstruction and bronchial hyperreactivity from patients with asthma whose airflow obstruction does not remit completely [18]. Therefore, when it comes to deciding if inhaled steroid treatment is apposite in a particular subject with apparent chronic obstructive airways disease, a pragmatic approach-which does not necessarily require definite diagnostic labelling - is needed to support GPs' decision-making.

In the current study, neither patients nor GPs were 'blinded', so both were well aware of the fact that inhaled steroid treatment was discontinued. Although from a methodological point of view a double-blind withdrawal trial would have been the preferred design, the results of such a trial would not reflect what happens in daily general practice if inhaled steroid treatment is discontinued in a subject with apparent COPD. As a consequence of our unblinded design patients may have been more perceptive to changes in respiratory symptoms which they normally would have ignored had their regular pharmacotherapy not recently been modified.

After inhaled steroid withdrawal, more than one-third (39\%) of our study subjects experienced an adverse respiratory outcome. This figure is very similar to findings reported by Jarad et al. [8], who observed that in a group of patients with COPD 38\% experienced an exacerbation within 8 weeks after regular inhaled steroid treatment had been discontinued in an unblinded manner. In their double-blind randomised controlled fluticasone propionate withdrawal trial, van der Valk et al. [10] observed a $48 \%$ exacerbation rate and an increased risk of recurrence during 6 month follow-up of their 142 patients with moderate to severe COPD recruited from hospital and outpatient records. O'Brien et al. [9] found that in elderly patients with severe irreversible airflow limitation, withdrawal of inhaled steroid therapy led to deterioration in ventilatory function and increased exercise-induced dyspnea. However, the heterogeneous primary care COPD population in our study will generally suffer from less severe disease and is likely to comprise more subjects with coexisting asthma features.

So far, only one subgroup analysis with regard to adverse effects of inhaled steroid withdrawal in COPD has been reported [8]. In this study of 272 patients with apparently irreversible COPD, no demographic or lung function variables predicted the risk of exacerbation after discontinuation of inhaled steroid treatment. Several large prospective placebo-controlled trials have explored the relative efficacy of inhaled steroids in subgroup analyses [1-3]. These subanalyses all considered heterogeneity of treatment effect with regard to the progressive $\mathrm{FEV}_{1}$ decline, but never explored the occurrence or frequency of exacerbations as an outcome of interest. In one study it was observed that inhaled steroids decelerated $\mathrm{FEV}_{1}$ decline in the subgroup with the least smoking history [2]. Other subject characteristics like age, gender, baseline $\mathrm{FEV}_{1}$, presence of serum IgE antibodies, reversibility of airflow limitation, or response to an oral corticosteroid trial did not predict the long-term treatment result of inhaled steroids in COPD, at least not in terms of $\mathrm{FEV}_{1}$ decline [1-3]. A small study performed in a mixed primary care population of patients with COPD and asthma indicated that current smoking, higher bronchodilator reversibility, low $\mathrm{FEV}_{1} / \mathrm{FVC}$ ratio and high annual lung function decline were related to a more progressive decline of $\mathrm{FEV}_{1}$ while on inhaled steroid treatment [19]. A recent subgroup analysis of a large inhaled steroid trial in secondary care patients suggest that the effects of inhaled steroids on exacerbations may be seen predominantly in patients with moderate-to-severe COPD who experience recurrent exacerbations [20]. Considering all published evidence on subject characteristics related to inhaled steroid treatment efficacy, there is some overlap with our findings: we observed that-next to gender and age-smoking status, degree of reversibility of airflow limitation and $\mathrm{FEV}_{1} / \mathrm{FVC}$ at the time of inhaled steroid withdrawal were related to adverse respiratory outcome.

In conclusion, when treatment with inhaled steroids is discontinued in patients with COPD, the probability of an adverse respiratory outcome is rather high, but it may be mediated by age, gender, smoking status and degree of reversibility of airflow limitation. Although the severity of airflow obstruction and the past exacerbation rate did not determine the probability of adverse outcome in our population, other studies have shown that these factors may be important determinants of relapse after inhaled steroid withdrawal as well. If in a patient with COPD discontinuation of inhaled steroid treatment is intended, a thorough prior assessment of potential determinants and careful monitoring of early signs and symptoms of an adverse respiratory response is well-advised.

\section{Announcement}

As a GP you will learn from our paper that ... discontinuation of prophylactic inhaled steroid treatment may harm patients with COPD, and that certain patient characteristics (i.e. age, gender, smoking status, severity and reversibility of airflow Available online at http://www.thepcrj.com Copyright GPIAG, reproduction prohibited 
limitation, past exacerbation rate) may predict adverse outcome after discontinuation of inhaled steroids in this group of patients.

\section{Acknowledgements}

The authors wish to thank all patients, general practitioners and practice assistants involved in the study for their contributions. This study was funded by the Dutch Council of Health Insurances. Additional financial support was provided by the Dutch Asthma Foundation.

\section{References}

[1] Burge PS, Calverley PMA, Jones PW, Spencer S, Anderson JA, Maslen TK. Randomised, double blind placebo controlled study of fluticasone propionate in patiens with moderate to severe chronic obstructive pulmonary disease: the ISOLDE trial. BMJ 2000;320:1297-303.

[2] Pauwels RA, Lofdahl CG, Laitinen LA, Schouten JP, Postma DS, Pride NB, et al. Long-term treatment with inhaled budesonide in persons with mild chronic obstructive pulmonary disease who continue smoking. New Engl J Med 1999;340:1948-53.

[3] Vestbo J, Sorensen T, Lange P, Brix A, Torre P, Viskum K. Long-term effect of inhaled budesonide in mild and moderate chronic obstructive pulmonary disease: a randomised controlled trial. Lancet 1999;353:1819-23.

[4] Wise MD, Connet J, Weinmann G, Scanlon P, Skeans M. Effect of inhaled triamcinolone on the decline in pulmonary function in chronic obstructive pulmonary disease. N Engl J Med 2000;343:1902-9.

[5] Pauwels RA, Buist AS, Calverley PM, Jenkins CR, Hurd SS. Global strategy for the diagnosis, management, and prevention of chronic obstructive pulmonary disease. NHLBI/WHO Global Initiative for Chronic Obstructive Lung Disease (GOLD) Workshop summary. Am J Respir Crit Care Med 2001;163:1256-76.

[6] Jackevicius CA, Chapman KR. Prevalence of inhaled corticosteroid use among patients with chronic obstructive pulmonary disease: a survey. Ann Pharmacother 1997;31:160-4.

[7] Roche N, Lepage T, Bourcereau J, Terrioux P. Guidelines versus clinical practice in the treatment of chronic obstructive pulmonary disease. Eur Respir J 2001;18: 903-8.
[8] Jarad NA, Wedzicha JA, Burge PS, Calverley PMA. An observational study of inhaled corticosteroid withdrawal in stable chronic obstructive pulmonary disease. Respir Med 1999;93:161-6.

[9] O’Brien A, Russo-Magno P, Karki A, Hiranniramol S, Hardin $M$, Kaszuba $M$, et al. Effects of withdrawal of inhaled steroids in men with severe irreversible airflow obstruction. Am J Respir Crit Care Med 2001;164:365-71.

[10] van der Valk P, Monninkhof E, van der Palen J, Zielhuis G, van Herwaarden C. Effect of discontinuation of inhaled corticosteroids in patients with chronic obstructive pulmonary disease: the COPE study. Am J Respir Crit Care Med 2002;166:1358-63.

[11] Chavannes NH, Schermer TRJ, Wouters EF, van Weel C, van Schayck CP. Treatment of COPD in general practice: the COOPT study. Eur Respir J 2001;18(Suppl 33):348s.

[12] Siafakas NM, Vermeire P, Pride NB, Paoletti P, Gibson J, Howard $\mathrm{P}$, et al. Optimal assessment and management of chronic obstructive pulmonary disease (COPD). Eur Respir J 1995;8:1398-420.

[13] Quanjer PH, Tammeling GJ, Cotes JE, Pedersen OF, Peslin $R$, Yernault JC. Lung volumes and forced ventilatory flows. Report Working Party Standardization of Lung Function Tests, European Community for Steel and Coal. Official Statement of the European Respiratory Society. Eur Respir J Suppl 1993;16:5-40.

[14] Collett D. Modelling survival data in medical research. London: Chapman \& Hall; 1994.

[15] MCMahon AD, MacDonald TM. Design issues for drug epidemiology. Br J Clin Pharmacol 2000;50:419-25.

[16] Tirimanna PR, van Schayck CP, den Otter JJ, van Weel C, van Herwaarden $\mathrm{CL}$, Van den Boom G, et al. Prevalence of asthma and COPD in general practice in 1992: has it changed since 1977. Br J Gen Pract 1996;46:277-81.

[17] van den Boom G, van Schayck CP, van Molken MP, Tirimanna PR, den Otter JJ, van Grunsven PM, et al. Active detection of chronic obstructive pulmonary disease and asthma in the general population. Results and economic consequences of the DIMCA program. Am J Respir Crit Care Med 1998;158:1730-8.

[18] American Thoracic Society. Standards for the diagnosis and care of patients with chronic obstructive pulmonary disease. Am J Respir Crit Care Med 1995;152:S77-120.

[19] van Schayck CP, Dekhuijzen PN, Gorgels WJ, van Grunsven PM, Molema J, van Herwaarden CL, et al. Are anti-oxidant and anti-inflammatory treatments effective in different subgroups of COPD? A hypothesis. Respir Med 1998;92:1259-64.

[20] Jones PW, Willits LR, Burge PS, Calverley PM. Disease severity and the effect of fluticasone propionate on chronic obstructive pulmonary disease exacerbations. Eur Respir J 2003;21:68-73.

\section{Available online at www.sciencedirect.com science $\mathcal{D}$ directo}

